\title{
CPC/15, A Primazia de Mérito e o Mandado de Segurança
}

\author{
Cpc / 15, The Primacy of Merit and the Writ of Mandamus
}

Jose Henrique Mouta'

\section{Resumo}

Este ensaio pretende analisar aspectos ligados à primazia de mérito no âmbito do Mandado de Segurança, com o aproveitamento do procedimento em caso de erro na indicação da autoridade e decadência.

Palavras-chave: Mandado de segurança; Mérito; Primazia

\begin{abstract}
This essay intends to analyze aspects related to the primacy of merit within the scope of the Writ of Mandamus, with the use of the procedure in case of error in the indication of the authority and statute of limitations.
\end{abstract}

Keywords: Writ of mandamus; Merit; Primacy.

\section{Introdução}

Este ensaio foi elaborado em homenagem ao centenário de nascimento do mestre Calmon de Passos que, dentro do seu vasto conhecimento e legado para a ciência do direito, é um dos escritores que mais se dedicou aos temas que serão aqui enfrentados ${ }^{1}$ ligados ao procedimento do mandado de segurança ${ }^{2}$.

Pretende-se, neste contexto, fazer o necessário contraponto entre a Lei do Mandado de Segurança (2009) e o Código de Processo Civil (2015).

A pergunta a ser enfrentada é a seguinte: será que há necessidade de repensar alguns institutos clássicos do MS considerando as normas fundamentais advindas da legislação processual comum e a primazia da resolução de mérito?

O legislador processual de 2015 consagrou um claro e necessário diálogo entre a teoria geral do processo e as normas fundamentais, estabelecendo institutos como a primazia da resolução de mérito, boa-fé processual, celeridade, efetividade e duração razoável do processo, fungibilidade e aproveitamento dos atos processuais, etc.

O texto, portanto, procura enfrentar aspectos ligados à aplicação da primazia da resolução de mérito no âmbito do Mandado de Segurança, com o afastamento de aspectos formais, especialmente

1 Esboço de uma teoria das nulidades aplicadas às nulidades processuais. Rio de Janeiro: Forense, 2009

2 Mandado de segurança coletivo, mandado de injunção, habeas data: constituição e processo. Rio de Janeiro: Forense, 1989. 
em relação aos institutos como a teoria da causa madura, aproveitamento da demanda em caso de incompetência em decorrência do erro na indicação da autoridade coatora e apreciação meritória mesmo ocorrendo a decadência.

Considerando o papel constitucional (art. 5o, LXIX e LXX) e a importância do mandado de segurança, não seria o caso de afastamento das formalidades processuais para estimular a resolução do mérito e efetivo controle jurisdicional dos atos do Poder Público? Como apontou o nosso homenageado Calmon de Passos:

"O agente administrativo, por mais violento, arbitrário e brutal que seja, permite antever-se a proteção do juiz, o império da decisão justa, que pune o excesso, reconduz as coisas e seus devidos limites e resgata o indivíduo da servidão a autoridade" .

Neste fulgor, vale lembrar que nenhum instituto processual pode ser analisado de forma isolada. Logo, visando a correta compreensão da possibilidade de apreciação do mérito do mandamus no que respeita ao controle da atuação estatal, superando aspectos e formalidades processuais, é necessário analisar as normas fundamentais previstas na legislação de 2015: cooperação (art. $6^{\circ}$, do CPC), primazia de mérito (art. 4º , do CPC), efetividade e celeridade, dentre outras.

Vamos aos argumentos.

\section{Decadência e denegação da segurança - possibilidades processuais - Análise da hipótese prevista no art. 488 , do CPC}

Questão que mantém ligação direta com a primazia de mérito e com a superação de formalidades processuais (art. 139, IX, do CPC), refere-se aos casos de decadência, em virtude da impetração do writ constitucional fora do prazo de 120 dias previsto na Lei no 12.016/09 - art. 23.

A própria constitucionalidade desta limitação temporal já provocou certa discussão doutrinária ${ }^{4}$. De toda sorte, há Enunciado de Súmula do STF sobre o assunto:

"Súmula 632. É constitucional lei que fixa o prazo de decadência para a impetração do mandado de segurança"

Superado este questionamento constitucional, cumpre apresentar duas reflexões: em se tratando de decadência, será que é vedada a utilização das vias comuns, considerando que há "resolução de mérito", nos termos do art. 487, II, do CPC/15? A decadência no MS é apenas um obstáculo procedimental, não impedindo outra demanda de controle do ato oriundo do Poder Público, desde que atendido ao prazo prescricional?

Vale partir de uma premissa: o prazo de $120 \operatorname{dias}^{6}$ é para a impetração do writ constitucional, pelo que a decadência refere-se apenas ao procedimento. Logo, assegura-se ao interessado o manejo de ação própria, dentro do prazo prescricional, ex vi do art. 19 da LMS.

3 CALMON DE PASSOS, José Joaquim. O mandado de segurança contra atos jurisdicionais: tentativa de sistematizado nos cinquenta anos de sua existência. Estudos e Pareceres, vol I. Salvador: Juspodivm, 2014, pp. 287-288.

4 Sobre o assunto, ver meu Mandado de Segurança. 7ํㅡㄹ ediçã Salvador: Juspodivm, 2019.

5 Não se deve olvidar que se trata de decisão de mérito atípica, considerando que o objeto (lide) não foi apreciado. De qualquer forma, a sentença que decreta a decadência será atingida pela coisa julgada material, a qual deverá ser enfrentada com muita cautela no mandado de segurança.

$6 \quad$ Não se deve olvidar que há a necessidade de se verificar se o caso concreto refere-se a ato único ou atos sucessivos. Nestes, o prazo decadencial renova-se à cada violação, como bem observa Hely Lopes Meirelles: "Nos atos de trato sucessivo, como no pagamento de vencimentos ou outras prestações periódicas, o prazo renova-se a cada ato e também não corre durante a omissão ou inércia da Administração em despachar o requerido pelo interessado". Mandado de Segurança, Ação Popular, Ação civil pública, mandado de injunção, 'habeas data', ação direta de inconstitucionalidade, ação declaratória de constitucionalidade e argüição de descumprimento de preceito fundamental. 26 a edição. São Paulo: Malheiros, 2003, p. 54. Ainda neste tema, indicam-se os seguintes precedentes: a) STJ - ROMS 13792, Relatora Min. Eliana Calmon. DJ de $05 / 05 / 2003$ PÁGINA:237); b) STJ - RESP 49960 - RS, Relator. Min Sálvio de Figueiredo Teixeira. DJ de: 23/06/2003). 
Em suma: trata-se de prazo ligado ao procedimento e não veda a propositura de outra demanda contra a fazenda pública, desde que atendido o prazo prescricional. Portanto, a "coisa julgada" ${ }^{7}$ decorrente da decisão denegatória do mandamus, não ultrapassa os limites do direito líquido e certo para atingir o fundo do direito.

Ademais, a decadência é considerada matéria de ordem pública, podendo ser decretada de ofício pelo órgão julgador. No tema, vale citar parte da Ementa do RMS 49973 / CE (STJ - 1ª T - Rel. Min. Benedito Gonçalves - J. em 10/11/2016 - DJe 25/11/2016):

"PROCESSUAL CIVIL. ADMINISTRATIVO. RECURSO EM MANDADO DE SEGURANÇA. DECADÊNCIA. OCORRÊNCIA. MATÉRIA DE ORDEM PÚBLICA. POSSIBILIDADE DE RECONHECIMENTO PELA INSTÂNCIA DE ORIGEM, MESMO QUE NA VIA DOS EMBARGOS DECLARATÓRIOS. 1. Esta Corte possui entendimento pacífico de que as matérias de ordem pública, tais como a decadência, podem ser reconhecidas a qualquer tempo nas instâncias ordinárias, mesmo no âmbito dos embargos de declaração, não estando sujeitas à preclusão. Precedentes: AgRg no REsp 1.287.754/MS, Rel. Min. Regina Helena Costa, Primeira Turma, DJe 02/02/2016; EDcl no AgRg no REsp 1.237.753/PR, Rel. Min. Nefi Cordeiro, Sexta Turma, DJe 13/02/2015; AgRg no AREsp 686.634/DF, Rel. Min. Moura Ribeiro, Terceira Turma, DJe 09/08/2016; EDcl no AgRg no AgRg no REsp 1.399.071/AL, Rel. Min. Humberto Martins, Segunda Turma, DJe 24/02/2014 (...) “.

De outra banda, considerando que a "coisa julgada" decorrente da decadência atinge apenas o procedimento especial mandamental, não poderá o interessado impetrar out ro writ. Como consequência, é discutível, inclusive, a analogia entre a decadência no MS e a hipótese prevista no art. 487, II, do CPC/15, eis que decisão, in casu, não impedirá a utilização de procedimento comum .

Este tema provoca o necessário diálogo com o princípio da primazia de mérito consagrado no CPC/15, através do enfrentamento da seguinte indagação: mesmo nos casos de decadência, é possível a denegação da segurança, com julgamento de mérito em favor do réu, à semelhança do previsto no art. 488, do CPC?

Ora, se for levado em conta que o prazo decadencial está ligado à perda de direito ao procedimento diferenciado ou mesmo à falta de interesse processual ${ }^{9}$, está correta a assertiva de que pode ser resolvido o mérito direto do mandado de segurança impetrado fora do prazo de 120 dias. Este raciocínio, para quem

$7 \quad$ Se é que se pode chamar desta forma, eis que o direito não foi atingido, mas apenas o instrumento (ação de mandado de segurança).

8 Aliás, sobre o assunto, vale transcrever a seguinte decisão: "Processo civil. Mandado de segurança - Decadência Art. 18 da lei $n^{\circ} 1.533 / 51$ - Nova impetração - Coisa julgada formal com efeitos materiais reduzidos. 1 - O reconhecimento da decadência instrumental, prevista no art. 18 da Lei no $1.533 / 51$, não importa, efetivamente, em provimento de mérito, mas sim em declaração da ausência de adequação da tutela mandamental em relação à vexata quaestio, o que deságua na carência de ação por falta de interesse processual e impõe a aplicação do art. 267, inciso VI, do Digesto Processual, não sendo caso, portanto, de extinção do feito com fulcro no art. 269, inciso IV, do mesmo Diploma Legal. 2 - Malgrado a extinção do processo sem exame de mérito não exclua a possibilidade de renovação da demanda, impõe-se ao Autor a correção da condição antes ausente, apresentando-se inviável o questionamento de aspectos que já foram decididos no feito anterior, os quais, por força da preclusão consumativa (artigos 471 e 473, do CPC), a respeito dos quais produzirá, a sentença terminativa, efeitos materiais reduzidos. 3 - Tendo em conta que o segurado já impetrou mandado de segurança objetivando restabelecer o pagamento de seu benefício previdenciário - comportando idênticos litigantes, causa de pedir e pedido -, tendo sido extinto referido mandamus, com base na decadência prevista no artigo 18 da Lei de Mandado de Segurança, cumpre observar, na espécie, o princípio da intangibilidade da coisa julgada, na medida em que renovado o pleito na via mandamental, devendo se submeter ao comando previsto no artigo 267, inc. V, do Digesto Processual. 4 Remessa necessária e apelação providas”. (TRF - 2ª Região - Apelação em Mandado de Segurança 41439 - Sexta Turma. Rel. Juiz Poul Erik Dyrlund. DJU data 10/06/2003).

9 Guilherme Freire de Barros Teixeira aponta nesta direção, ao aduzir, no item 11 das conclusões de ensaio publicado na RePro (antes da Lei 12.016/09), que: "o decurso do prazo previsto no art. 18 da LMS conduz ao reconhecimento da falta de interesse de agir, pela inadequação da via eleita, devendo ser reconhecida a carência de ação, mas com as conseqüências mencionadas, que, no entanto, no caso específico do mandado de segurança, não são relevantes, já que basta ao interessado pleitear o reconhecimento do seu alegado direito pelas “vias ordinárias'”. Natureza jurídica do prazo para impetração do mandado de segurança. Revista de Processo no 149. São Paulo: Revista dos Tribunais, julho de 2007 , p. 27. 
entende que a decadência está ligada à falta de interesse processual ${ }^{10}$, caminha no sentido de aplicação da teoria da asserção, eis que, a condição da ação (decadência do MS) estaria ultrapassada quando analisado o mérito da demanda mandamental.

Destarte, a primazia da solução de mérito permite, mesmo em casos de decadência, a solução definitiva do objeto litigioso. Portanto, partindo desta premissa e se acaso tenha ocorrido o aprofundamento do juízo cognitivo do magistrado (após as informações da autoridade coatora e a manifestação do Ministério Público), será possível a denegação da segurança mesmo tendo sido impetrado fora dos 120 dias.

Esta conclusão está em consonância com os arts. 4º, 139, IX e, mais especificamente, com o art. 488, do CPC, que consagra a resolução de mérito sempre que for favorável à parte a quem aproveitaria eventual pronunciamento de natureza processual (art. 485, do CPC). A resolução de mérito é secundum eventum litis, permitindo apenas a denegação da segurança mesmo em caso de impetração fora do prazo de 120 dias.

Aqui é necessário fazer uma importante ressalva: ao contrário das hipóteses inerentes à aplicação da teoria da causa madura no julgamento da apelação ou do RMS (recurso ordinário em mandado de

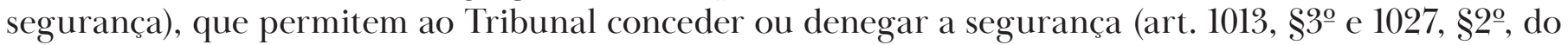
CPC), o art. 488, do CPC, consagra apenas a resolução meritória favorável à parte que iria se aproveitar pelo julgamento de natureza processual. Portanto, tendo a decadência natureza processual, o magistrado pode apreciar o mérito do MS, desde que seja para denegar a segurança.

O próprio sistema processual de 2015 consagra a necessidade de solução definitiva da relação material deduzida em juízo com celeridade e efetividade, pelo que não faz sentido decretar a decadência no âmbito do MS e, em nova demanda, o Poder Judiciário julgar o pedido improcedente.

Esse tema já foi apreciado no STJ, senão vejamos:

"MANDADO DE SEGURANÇA. ADMINISTRATIVO. PREVIDENCIÁRIO. PROCESSO CIVIL. ILEGITIMIDADE PASSIVA. DECADÊNCIA DO DIREITO DE IMPETRAÇÃO. ATO COMISSIVO, E NÃO OMISSIVO. PRINCÍPIO DA PRIMAZIA DA DECISÃO DE MÉRITO. MARÍTIMO SERVIDOR AUTÁRQUICO. AUSÊNCIA DE COMPROVAÇÃO DE ENQUADRAMENTO NO MINISTÉRIO DO TRABALHO. PEDIDO DE APROVEITAMENTO E CONVERSÃO PARA APOSENTADORIA COMPULSÓRIA. IMPOSSIBILIDADE. FALTA DE PREVISÃO LEGAL PARA CUMULAÇÃO DOS BENEFÍCIOS. PRECEDENTES DO TRIBUNAL FEDERAL DE RECURSOS E DO SUPERIOR TRIBUNAL DE JUSTIÇA. 1. Trata-se de Mandado de Segurança em que o impetrante, que pertenceu ao quadro da Lloyd Brasileiro, requer seu imediato aproveitamento e a conversão para a condição de aposentado, bem como o pagamento dos respectivos valores, considerada a prescrição, a partir do Decreto 62.938/1968 c/c a Lei 1.711/1952 e a Lei 8.112/1990. 2. Embora a autoridade apontada como responsável pelo ato omissivo ilegal (Ministro do Transporte) não seja, atualmente, competente para reaproveitar e aposentar o requerente, tem-se que o ato é, em verdade, comissivo, consistente no Despacho que negou expressamente o enquadramento almejado. 3. Nos termos do art. $6^{\circ}$, $§ 3^{\circ}$, da Lei 12.016/2009, é parte legítima não somente quem pode executar diretamente o ato, mas quem delegou essa possibilidade. Não se exige, quanto à legitimidade, que o impetrante conheça toda a distribuição de competências do órgão em que atua a autoridade. 4. A decisão denegatória expressa, aposta no Processo $\mathrm{n}^{\circ}$ 14.261-98, afasta a hipótese de ato coator omissivo e leva à verificação da decadência para impetrar o Mandado de Segurança. 5. Não obstante a decadência do direito de impetração, de forma excepcional, à luz dos princípios da primazia da decisão de mérito, previsto nos arts. $4^{\circ}$ e $6^{\circ}$ do CPC de 2015; da duração razoável do processo; da celeridade; da instrumentalidade das formas, bem como da aplicação analógica dos arts. 139, IX e 1.029, § 3º , do CPC de 2015, não é o caso de se extinguir o presente Mandado de Segurança sem adentrar o mérito da demanda, pois o ajuizamento da demanda se deu há mais de 3 (três) anos, e a causa está pronta para julgamento, com documentos e argumentos lançados por ambas as partes. 6. Ademais, e mais importante, a segurança é manifestamente

10 Mais uma vez vale citar as lições do nosso homenageado Calmon de Passos, quando trata das condições da ação: "sempre afirmei e continuo afirmando que essas tais condições da ação, em verdade, outra coisa não são que pressupostos da relação jurídica colocada como mérito do processo. Ela, como toda relação jurídica, também tem seus pressupostos, requisitos e condições". Esboço de uma teoria das nulidades aplicadas às nulidades processuais. Rio de Janeiro: Forense, 2009, p. 117. 
incabível, sendo desarrazoado extinguir o writ sem apreciar o direito material do impetrante, que poderia acessar as vias processuais ordinárias demandando a formação de uma nova relação processual. 7. Por ser manifestamente inadmissível, caberia a pronta denegação da segurança por decisão monocrática (art. 212 do Regimento Interno), o que permitiria a análise do mérito. Consequentemente, e diante dos fundamentos expostos, é de se permitir tal análise neste momento do processo. 8. O nome do impetrante não consta na lista anexa ao Decreto 62.938/1968, de modo que não foi integrado ao quadro do Ministério do Trabalho. 9. Ainda que tivesse ocorrido, os marítimos não possuem direito à percepção cumulativa de duas aposentadorias, uma pelo Regime Próprio da União e outra pelo Regime Geral da Previdência Social. Interpretação da Lei 2.752/1956 que não prevê a referida acumulação para os servidores autárquicos, seja da Lloyd Brasileiro, seja da Companhia Costeira. Precedentes. 10. Segurança denegada” (MS 20295- 1ª Seção - Rel. Min. Herman Benjamim. J. em 9.11.2016 -DJe 29/11/2016)

No STF, vale a análise do MS 25097 (J. em 28.03.2017), de Relatoria do Min. Gilmar Mendes ${ }^{11}$, onde a $2^{\text {a }}$ Turma concedeu a segurança levando em conta que o caso concreto envolvia medida liminar concedida muito anos antes. Vale transcrever passagem do voto do Ministro Relator:

"Transcorridos mais de doze anos, é de questionar atualmente a pertinência de eventual reconhecimento puro e simples de decadência do direito de impetração do mandado de segurança”.

Estas reflexões devem ser objeto de análise cautelosa, tendo em vista que no MS, como já mencionado, a decadência atinge apenas o procedimento ${ }^{12}$. Logo, levando em conta a primazia da resolução de mérito consagrada na legislação processual posterior à Lei 12.016/09, deve ser ultrapassada a decadência para a apreciação da segurança pleiteada.

Não se vislumbra qualquer impedimento na sua superação, apenas em caso de denegação da segurança, atendendo-se, em consequência, às normas processuais do CPC, como bem identificou o STJ no julgamento do MS 20295. Ora, se a denegação permitirá a utilização das vias procedimentais comuns, importante refletir se para o alcance da primazia de mérito não é melhor superar esse entrave e apreciar logo o mérito (causa de pedir e pedido) postulado em juízo, com a denegação da segurança, nos termos do art. 488 do CPC.

Esta é conclusão. Este é o convite para reflexão: aplicar o art. 488, do CPC no âmbito do MS, para superar entraves procedimentais (como a decadência) e apreciar desde logo o objeto litigioso, com decisão final e de mérito favorável ao polo passivo.

A contrário senso, na decisão do STF citada acima, a Corte superou a decadência para conceder a segurança o que, apesar das circunstâncias do caso concreto, não encontra assento na literalidade do disposto no art. 488, do CPC.

Portanto, cabe ao estudioso a análise do princípio da primazia de mérito no âmbito do Mandado de Segurança, garantindo-se, de um lado, a utilização desta importante ação constitucional e, de outro, o atendimento aos ditames estruturais da legislação processual de 2015.

11 "Mandado de Segurança. 2. Ato do TCU. Suposta cumulação indevida de proventos. Suspensão dos pagamentos. 3. Decadência. Verificação de impetração do mandamus em data posterior ao prazo de 120 dias da ciência do ato impugnado. Superação. Medida liminar concedida há mais de doze anos. Preservação da segurança jurídica. Precedentes do STF. 4. Cumulação de proventos e pensões. Cargos públicos inacumuláveis em atividade. Regimes civil e militar. Concessão anterior à Emenda Constitucional 20/1998. Possibilidade. Precedentes. 5. Segurança concedida”.

12 Supera-se, portanto, o defeito de forma para alcançar o objeto litigioso. Como bem aponta Calmon de Passos: "no direito público, bem como no âmbito das normas cogentes, a invalidade é correlacionada à consequência antes que um suposto normativo, falando-se, na espécie, em fungibilidade das formas ou dos tipos. A ordem jurídica valida o comportamento atípico, tendo em vista a sua adequada instrumentalidade prática para lograr o fim perseguido". Esboço de uma teoria das nulidades aplicadas às nulidades processuais. Rio de Janeiro: Forense, 2009, p. 32. 


\section{Correção da autoridade coatora e contagem dos prazos processuais}

Outra questão importante no que respeita à aplicação do CPC/ 15 no procedimento do mandado de segurança com superação de alguns aspectos formais refere-se ao erro na indicação da autoridade coatora e a possibilidade de sua modificação, mesmo quando isso gere a modificação da competência para conhecimento e julgamento do writ.

Ora, se o legislador processual de 2015 permite, por exemplo, correção do polo passivo (arts. 338 e 339), manutenção dos atos decisórios proferidos por órgão incompetente (art. 64, §4ํ), aproveitamento de ação rescisória proposta perante Tribunal incompetente (art. 968, §5º), a ampliação do juízo de retratação nos casos de decisão sem resolução de mérito (art. 485, §6º e 488), é razoável defender que, como instrumento de alcance da primazia de mérito ${ }^{13}$, é admissível a correção da autoridade coatora do procedimento mandamental, visando o atendimento às normas fundamentais já citadas neste ensaio.

Neste fulgor, os Enunciados 488 e 511, do Fórum Permanente de Processualistas Civis consagram, respectivamente: "No mandado de segurança, havendo equivocada indicação da autoridade coatora, o impetrante deve ser intimado para emendar a petição inicial e, caso haja alteração de competência, o juiz remeterá os autos ao juízo competente" e: "a técnica processual prevista nos arts. 338 e 339 pode ser usada, no que couber, para possibilitar a correção da autoridade coatora, bem como da pessoa jurídica, no processo de mandado de segurança”.

Contudo, a interpretação do STJ é variável. Este equívoco por parte do impetrante em relação à autoridade coatora pode ocasionar, se alterar a competência Jurisdicional ou se a mesma for vinculada a outra pessoa jurídica de direito público, a extinção do processo (no STJ: AgInt no RMS 51.527/GO, Rel. Ministro Sérgio Kukina, 1aㅡ T, julgado em 18/10/2016, DJe 04/11/2016; AgRg nos EDcl no RMS 45.074/PE, Rel. Ministro Mauro Campbell Marques, 2ª T, julgado em 05/08/2014, DJe 12/08/2014) ou a correção pelo próprio Poder Judiciário, inclusive em atendimento ao art. 338, do CPC.

Vale citar a Ementa do AgInt no REsp 1505709 / SC ( STJ - 1aㅡ Turma - Rel. Min. Gurgel de Faria - J. em 23/06/2016 - DJe 19/08/2016).

"PROCESSUAL CIVIL. AGRAVO INTERNO EM RECURSO ESPECIAL. VIOLAÇÃO AO ART. 535 DO CPC/1973. NÃO DEMONSTRAÇÃO. SÚMULA 284 DO STF. MANDADO DE SEGURANÇA. EMENDA À INICIAL. CORREÇÃO DA AUTORIDADE APONTADA COATORA. MODIFICAÇÃO DE COMPETÊNCIA TERRITORIAL. IMPOSSIBILIDADE. 1. "É inadmissível o recurso extraordinário, quando a deficiência na sua fundamentação não permitir a exata compreensão da controvérsia” (Súmula 284 do STF). 2. Hipótese em que a recorrente não teceu nenhuma fundamentação concreta que justificasse a sua irresignação quanto à violação do art. 535, II, do CPC/1973, o que atrai o óbice de conhecimento. 3. O Superior Tribunal de Justiça admite a emenda à petição inicial de mandado de segurança para a correção de equívoco na indicação da autoridade coatora, desde que a retificação do polo passivo não implique, diversamente do que ocorreu no caso, alterar a competência judiciária e desde que a autoridade erroneamente indicada pertença à mesma pessoa jurídica da autoridade de fato coatora. Precedentes. 4. O mandado de segurança foi extinto sem resolução de mérito, prejudicando a análise da alegada violação ao art. 22, I, da Lei n. 8.212/1991, arts. 26 e 79 da Lei n. 11.941/2009, art. 74 da Lei n. 9.430/1996, arts. $3^{\circ}$ e $4^{\circ}$ da Lei Complementar n. 118/2005 e art. 170-A do CTN, por ausência de prequestionamento (Súmula 282 do STF). 5. Agravo interno desprovido"

Entendo que, essa extinção do processo em decorrência do erro na indicação da autoridade e alteração de competência é mais um obstáculo formal que deve ser superado, para que se garanta a análise do mérito do MS e atendimento às normas fundamentais do CPC, especialmente pelo curto prazo para a nova impetração.

Portanto, sempre que possível e atendendo aos requisitos consagrados pela legislação processual (arts. 139, IX, 338 e 339, do CPC), defende-se a possibilidade de correção da autoridade coatora indicada

13 Sobre a primazia de mérito no CPC/ 15 , indica-se a leitura dos seguintes dispositivos: arts. $4^{\circ}, 6^{\circ}, 139$, IX, 282, $\$ 2^{\circ}$,

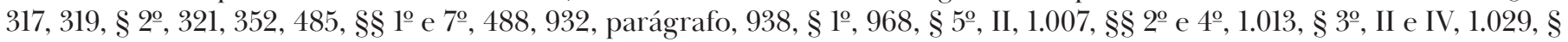
$3^{\circ}, 1032$ e 1.033$)$, além do art. 338. 
pelo autor, prosseguindo o feito com a sua redistribuição como instrumento de alcance da primazia de mérito.

De toda sorte, é fato que um dos grandes obstáculos para esse trânsito procedimental dar certo é que no Brasil existem vários sistemas eletrônicos nos diversos tribunais que fazem parte do Sistema de Justiça, muitos dos quais incomunicáveis. Superado esse entrave, o deslocamento sem a extinção permite a sobrevida do mandado de segurança e, em última análise, a possibilidade de manutenção deste procedimento especial.

O derradeiro aspecto a ser aqui discutido refere-se à contagem do prazo no mandado de segurança e a aplicação do art. 219, do CPC.

Neste contexto, devem ser separados os prazos para impetração e aqueles que correm dentro do procedimento. O primeiro é prazo material e deve ser contato em dias corridos, enquanto os prazos para informações, recursos e outras manifestações devem ser contados em dias úteis, nos termos do art. 219, do CPC. ${ }^{14}$

O STF já apreciou a questão ${ }^{15}$. Vale citar a Ementa do AgReg no MS 34.941/ES (2ª Turma - Rel. Min. Edson Fachin - Sessão Virtual de 27.10.2017 a 6.11.2017 - DJe 05/12/2017):

AGRAVO REGIMENTAL. MANDADO DE SEGURANÇA. PROMOTORA DE JUSTIÇA ESTADUAL. CNMP. APLICAÇÃO DE PENALIDADE. LITISPENDÊNCIA. DECADÊNCIA DO DIREITO À IMPETRAÇÃO. INAPLICABILIDADE DO ART. 219 DO CPC. DESPROVIMENTO DO AGRAVO.

1. A reprodução de ação ainda em curso configura, nos termos do art. 337, § 3º do Código de Processo Civil, litispendência, o que implica o indeferimento da inicial sem julgamento de mérito.

2. In casu, a impetrante já ajuizou mandado de segurança com o objetivo de desconstituir precisamente a decisão proferida no processo 1.00443/2015-76 que lhe aplicou a penalidade de advertência.

3. O novo Código de Processo Civil, ao alterar a sistemática da contagem de prazos, estipulando o cômputo somente dos dias úteis, o fez única e exclusivamente em relação aos prazos processuais, nos termos do parágrafo único do artigo 219.

4. Não se tratando de prazo processual, descabe cogitar a incidência do art. 219 do CPC ao prazo decadencial de 120 (cento e vinte) dias estabelecido para a impetração do mandado de segurança (art. 23 da Lei 12.016/09).

5. Agravo regimental a que se nega provimento"

Assim, ao aplicar o CPC no procedimento mandamental, deve o intérprete separar os prazos em dois grupos: 120 dias para a impetração e os para prestar informações, recorrer, cumprir a medida liminar eventualmente concedida, etc.

Trata-se, portanto, de mais um aspecto a provocar o necessário diálogo entre as legislações de 2009 e de 2015. Um convite à reflexão, inclusive superando as formalidades processuais previstas na lei especial, como apontado neste texto.

\section{Conclusões}

Em face do exposto, é possível concluir que:

- O legislador processual de 2015 consagrou um claro e necessário diálogo entre a teoria geral do processo e as normas fundamentais, estabelecendo institutos como a primazia da resolução de mérito, boa-fé processual, celeridade, efetividade e duração razoável do processo, fungibilidade e aproveitamento dos atos processuais, etc.

14 O Enunciado 11 do FNPP possui a seguinte redação: “(art. 219, parágrafo único, Lei 13.105/15; art. 7º , Lei 12.016/09) Os prazos processuais no mandado de segurança são contados em dias úteis, inclusive para as informações da autoridade coatora". 
- Visando a correta compreensão da possibilidade de apreciação do mérito do mandamus no que respeita ao controle da atuação estatal, superando aspectos e formalidades processuais, é necessário analisar as normas fundamentais previstas na legislação de 2015: cooperação (art. $6^{\circ}$, do CPC), primazia de mérito (art. $4^{\circ}$, do CPC), efetividade e celeridade, dentre outras.

- É discutível a analogia entre a decadência no MS e a hipótese prevista no art. 487, II, do CPC/15, eis que decisão, in casu, não impedirá a utilização de procedimento comum.

- A primazia da solução de mérito permite, mesmo em casos de decadência, a solução definitiva do objeto litigioso, com a denegação da segurança mesmo tendo sido impetrado o writ fora dos 120 dias.

- O sistema processual de 2015 consagra a necessidade de solução definitiva da relação material deduzida em juízo com celeridade e efetividade, pelo que não faz sentido decretar a decadência no âmbito do MS e, em nova demanda, o Poder Judiciário julgar o pedido improcedente.

- Logo, é possível aplicar o art. 488, do CPC no âmbito do MS, para superar entraves procedimentais (como a decadência) e apreciar desde logo o objeto litigioso, com decisão final e de mérito favorável ao polo passivo.

- A extinção do processo em decorrência do erro na indicação da autoridade e alteração de competência é mais um obstáculo formal que deve ser superado, para que se garanta a análise do mérito do MS e atendimento às normas fundamentais do CPC, especialmente pelo curto prazo para a nova impetração.

- Por derradeiro, no âmbito do MS, devem ser separados os prazos para impetração e aqueles que correm dentro do procedimento. O primeiro é prazo material e deve ser contato em dias corridos, enquanto os prazos para informações, recursos e outras manifestações devem ser contados em dias úteis, nos termos do art. 219, do CPC.

\section{Referências}

ARAÚJO, José Henrique Mouta. Mandado de Segurança. 7ํa edição. Salvador: Juspodivm, 2019.

CALMON DE PASSOS, José Joaquim. Esboço de uma teoria das nulidades aplicadas às nulidades processuais. Rio de Janeiro: Forense, 2009.

. Mandado de segurança coletivo, mandado de injunção, habeas data: constituição e processo. Rio de Janeiro: Forense, 1989.

O mandado de segurança contra atos jurisdicionais: tentativa de sistematizado nos cinquenta anos de sua existência. Estudos e Pareceres, vol I. Salvador: Juspodivm, 2014.

MEIRELLES, Hely Lopes. Mandado de Segurança, Ação Popular, Ação civil pública, mandado de injunção, 'habeas data', ação direta de inconstitucionalidade, ação declaratória de constitucionalidade e argüição de descumprimento de preceito fundamental. 26ª edição. São Paulo: Malheiros, 2003.

TEIXEIRA, Guilherme Freire de Barros. Natureza jurídica do prazo para impetração do mandado de segurança. Revista de Processo no 149. São Paulo: Revista dos Tribunais, julho de 2007. 